\title{
A Sense-Making Approach to Understanding Adolescents' Selection of Health Information Sources
}

\author{
Rocco De Pietro, PhD, \\ Noreen M. Clark, PhD
}

The authors propose that information sources are best understood as constructed by individuals in an attempt to find answers to questions of immediate relevance. Contact profiles, or patterns of source use for particular information. determine what constitutes a source for an individual. The study explores how adolescents acquire and use health information. Data analyses based on a probability sample of 200 adolescents identified nine contact protiles and supported four study hypotheses. Contact profiles differ according to health topics and are related to message sending and seeking regarding human sexuality and birth control. Adolescents with peer-media, home-oriented or multi-source contact profiles about human sexuality and birth control were more likely than others to be the peer advisors on this topic, and those with peer-media and multi-source profiles the ones more likely to be the information seekers about it. Contact profiles are also related to adolescents' health decision making capacity. Adolescents with peer-media and multi-source profiles for human sexuality and birth control information and those with homeoriented profiles for alcohol and smoking information engaged in more health decision making steps than those with other profiles. Finally, contact profiles are also related to awareness and contact with new information sources. Adolescents with peer-oriented and multi-source profiles were more likely than others to be aware of and have contacted a new peer education program in the school.

\section{INTRODUCTION: SOURCES AS CONSTRUCTIONS}

In much of the mass communication research literature. an information source is viewed as something concrete that derives its meaning apart from the people who use it. From this perspective, a health information source, that is a person or a medium such as a television program or a brochure with information potential, is imbued with certain qualities that affect its capacity to store, process and diffuse information regarding health. Well-documented in the persuasion literature. ${ }^{1-3}$ these qualities often

Rocco De Pietro is from the Department of Health Bchavior and Health Education and the Center for Population Planning. The University of Michigan School of Public Health. Noreen M. Clark is from the Department of Health Behavior and Health Education. The University of Michigan School of Public Health.

Address reprint requests to Rucco De Pietro, PhD, 1420 Washington Heights, Ann Arbor, MI 48109. 
pertain to such characteristics as source credibility. attractiveness, power, and accessibility. From this source perspective, users of health information are recipients of "message symbols," or content, from various sources. The manipulation of source qualities is viewed as sufficient to produce communication effects on a user, such as increased attention to, comprehensive of, or yielding to information. From the source perspective, health information users also have qualities, such as their demographic characteristics, personality, attitudes, cognitive styles, preferences for media and content, which serve to moderate source influences. However, the logic of this perspective is based on the idea that success in reaching audiences lies in the matching of source and user characteristics.

In this article. we argue that information sources do not exist in any objective sense for potential users. They only exist in a relative sense. They are constructed by users who see them as providing answers to their questions that have meaning in the users' time and space. Dervin has suggested that information is constructed by users. ${ }^{\perp 7} \mathrm{We}$ posit that, just as information is constructed. so is an information source constructed. People construct a health information source based on the expectation that the source will help them to answer the type of questions that are relevant to their own health situation. From these sources, people proceed to construct information, that is, acquire answers to particular questions they have.

Dervin has theorized that people. in attempting to make sense out of their world. seek information that is helpful in navigating life's many passages. People seek answers to design their next move through time and space. ${ }^{5}$ We expand on this perspective by suggesting that a source is only a source if it is connected with an individual's need for information. and. more specifically. to information that is needed to facilitate movement through time and space. Information enables one to order and interpret the environment and subsequently to make decisions and take actions. Putting information to use is an extension of sense making. ${ }^{4}$

The perspective that sees sources and information as consiructed by an information user for purposes of "sense making" suggests that: (1) an information source is only a source if some user perceives that it is: (2) contacts with a potential information source alone is insufficient to account for "effects" of sources; (3) people use different sources for different types of information; and (4) people use information for a variety of reasons, some of which will be unknown or unanticipated by the information source.

\section{SOURCE CONTACT PROFILES AS USER CONSTRUCTS}

Some sources are more likely than others to aid sense making, or the movement of people through time and space. Information can help one to get started, keep going, find new roads to travel, and avoid pitfalls. ${ }^{4}$ Over time, we suggest, people develop contact profiles, or patterns of source use. Contact profiles are important because they represent an individual's best estimate of where to obtain the type of information that aids movement. As topics change, contact profiles are likely to change.

Of course. real and perceived barriers can operate to constrain the selection of an information source. ${ }^{8.9}$ A source might be or be perceived as "not approachable" or inaccessible for certain types of information. In some cases, these barriers can result in the development of a narrower contact profile than might otherwise exist. However, 
in most cases. we expect that contact profiles represent freely selected patterns of source usage.

Contact profiles set the parameters of people's movement through time and space. For some, they facilitate movement, and for others they serve as formidable constraints to movement. For example, some people perceive that family members and friends are sources of helpful health information. Interaction with these sources is very likely to involve discussion that is needed to process complex or novel stimuli. ${ }^{10}$ Similarly, information from sources which present diverse perspectives on a subject, can facilitate movement by requiring mental elaboration, e.g., reconciling differing points of view or weighing alternative suggestions. People who have multiple and diverse source contact might be more able to put information to use than. say, people who have a source that offers limited opportunities for social interaction.

\section{COMPARISON OF USER SENSE MAKING AND SOURCE PERSPECTIVES}

Let us compare for a moment the "source" perspective with the "user sense-making" perspective. From a source perspective. people's use of information sources is based on differences in demographic or socio-economic characteristics. Because some are young. female, black, or high income they tend to prefer different information sources. For example, older people are said to read health magazines because they are more likely than younger people to have health problems. A user sense making perspective suggests that people use different sources, or combinations of sources, because they meet their immediate information needs. Old people or young people might read a health magazine depending on how the magazine answers questions about their own health status or the health status of someone who is important to them. The health situation of people, not their age, is the key to understanding whether such a magazine will be viewed as an information source.

From a source perspective, an information source functions as a source as long as it continues to hold and provide information. From a user sense niaking perspective, a source remains a source only as long as people perceive it capable of answering questions or responding to personal needs.

From a source perspective. the notion of source preference usually means that a person depends on a single source. one that is most highly valued for information on a specific topic. It does not take into account the pattern of source use that might include several sources. For example. an adolescent might state a preference for contact with peers for health information, but his or her actual behavior may show extensive contact with media and professionals as well. While a preferred source, peers might not be able to provide certain types of information, for example. information that may be taboo."

\section{CONTACT PROFILES DEFINED}

We define contact profiles based on the opportunities which they provide for information acquisition and social interaction. Profiles can be single source profiles. such as contact mainly with peers. media, professionals or family. They can be hybrid 
profiles, such as contact with mainly two of these groups, e.g.. peer and media. Finally, they can be multi-source, such as high level contact with many different kinds of sources. For example. in the case of a hybrid profile, high levels of contacts with both peers and media might provide opportunities for social interaction plus salient and sufficient health information regarding certain topics. Heavy contact with only one or the other source would not provide the added benefit. From a user sense-making perspective, it is the individual possessing a contact profile with the greatest potential synergism between information and social interaction who has an edge in making sense of information and putting it to use.

\section{Study Hypotheses}

Based on the user sense making perspective, we have developed four hypotheses with respect to adolescents' contact profiles for health information.

\section{H1: Contact Profiles Differ Across Different Topics}

Adolescents are likely to have different contact profiles for different types of information. The choice is a function of adolescents' assessment of how useful certain sources will be to help them solve specific problems or pursue particular interests.

\section{H2: Contact Profiles Constrain Message Sending and Message Seeking}

Contact profiles constrain adolescents' message sending because they determine the information adolescents bring to a situation and the usefulness of the adolescent as a source of information for others. For example, adolescents with hybrid contact profiles, such as those who rely on peers and media or peers and professionals for certain types of information, might be expected to have more or better information than those who rely primarily on a single source.

Contact profiles constrain adolescents' message seeking by structuring the paths through which information is sought. An individual with a multi-source contact profile has many pathways to information, whereas one with a single source profile has a few, highly selective paths.

\section{H3: Contact Profiles Are Related to the Capacity to Make Important Health Decisions}

Contact with certain health information sources should affect adolescents' capacity to make important health decisions. Because of their contact profile, individuals will be exposed to information of particular quality, potential usefulness, and accuracy. ${ }^{12}$ In addition. those who make frequent use of multiple sources have greater opportunities for social interaction and mental elaboration. Such individuals are likely to get more feedback and help with making a health decision, or trying out a decision. 


\section{H4: Contact Profiles Will Affect Awareness and Use of New Sources of Information}

Contact profiles affect awareness of novel information. For example, adolescents with a peer contact profile, might learn about a new family planning peer education program because of their contact with other peer sources. An adolescent who only seeks family planning information from his parents might not learn about the novel program. An adolescent with a media profile might learn about the new program if the media carry messages about it.

In order to test empirically these hypotheses, a study was undertaken.

\section{METHODOLOGY}

The sample consisted of 200 adolescents, between the ages of 15 to 18 , selected at random from official lists of a school district in southwestern Michigan. Of the entire sample. $59.8 \%$ were female. $40.2 \%$ male: $81.5 \%$ white, and $18.5 \%$ non-white; $72.5 \%$ were from families in which both mother and father were present, and $27.5 \%$ lived in some other type of family arrangement. The mean age of the sample of adolescents was 16.3 .

Adolescents and their parents were sent consent forms and letters asking them to participate as resource persons in an evaluation of health information systems for young people. Those who consented were asked to complete a 20 -minute self-administered questionnaire in the presence of a trained interviewer. The percentage of adolescents who refused to participate was $25 \%$. The reason most frequently given for refusing was personal inconvenience.

\section{Measures of Contact Profiles}

Two types of information were used to determine adolescents' contact profiles: human sexuality and birth control; and alcohol and smoking. Respondents were asked to report the sources they had actually contacted for each topic of information. In totai, forty-one sources were listed for respondents to consider.

We measured contact profiles by determining the amount of contact adolescents had with four categories of information sources: family, including parents, siblings, and other relatives; peers, including same and opposite sex friends, and peer educators; professionals, including doctors, nurses, counselors, and teachers; and mass media, including broadcast media, printed materials, hotlines, and films. We distinguished among single, hybrid and multi-source contact protiles. Single source profiles meant predominant contact with either family, peers, professionals or media. To qualify as a single source contact profile respondents had to indicate more contact with one of these sources than any of the other combined. This methodology is similar to that used in network analysis when assigning individuals to groups. ${ }^{13}$

Three types of multi-source profiles were distinguished: multi-source low, where there was low contact with several sources without one being the dominant one; multisource high, where there was high contact with a variety of sources without any one 
being the dominant one; and hybrid, where there was high contact with two sources and low contact with two others, e.g., high in peer and media while low in professional and family.

The percent of contact profiles in the sample for information regarding human sexuality and birth control and alcohol and smoking are shown in Table 1.

For each type of information, about half the adolescents had multi-source high and multi-source low profiles. About another one-quarter were hybrid users. The remaining one-quarter were the single-source contact profiles.

Measures of source contact do not take into account the number of exposures to specific sources or the ultimate value of these contacts to the adolescents. They simply take into account the presence or absence of communication linkages and the variety of these linkages.

\section{Measures of Communication Behavior}

Four measures of communication behavior were included in the questionnaire. The first measure was awareness of a new information source. The source in this case was a school-based peer education program on human sexuality and birth control. The second measure was contact with the new source. The third was health decision making capacity, determined by whether adolescents engaged in certain processes when making a recent health decision. This measure included 13 steps which individuals often take when making important health decisions: looking for information, weighing the advantages and disadvantages of a decision, trying out the decision to see if it works, looking for support for one's decision, and so forth. The 13-item scale had good internal reliability (alpha $=.71$ ).

Fourth, was a measure of message sending. This included the willingness of adolescents to give advice to friends about the two types of health information: birth control use, and smoking and alcohol use.

\section{ANALYSIS OF RESULTS}

We found considerable support for the four major hypotheses. With respect to $\mathrm{Hl}$, contact profiles did differ across types of information (see Table 2). However, there

Table 1. Adolescents' Contact Profiles for Two Types of Information (Percentages)

\begin{tabular}{lrc}
\hline \multicolumn{1}{c}{ Contact Protile } & Sexuality & Alcohol and Smoking \\
\hline Home-Oriented & 6.8 & 3.8 \\
Peer-Oriented & 10.0 & 6.8 \\
Media-Oriented & 5.3 & 7.8 \\
Professionally-Oriented & 1.1 & 4.7 \\
Multi-Source High & 34.2 & 27.6 \\
Multi-Source Low & 16.3 & 20.8 \\
Hybrid (Peer\&Prof) & 12.6 & 9.9 \\
Hybrid (Peer\&Media) & 4.7 & 5.2 \\
Hybrid Other & 8.9 & 13.5 \\
\hline
\end{tabular}


Table 2. Similarity of Source Contact Profiles Across Two Categories of Health Information*

\begin{tabular}{lc}
\hline Type of Contact Profile & $\begin{array}{c}\text { Adolescents with Same } \\
\text { Profile Across Topics } \\
\text { (Percentages) }\end{array}$ \\
\hline Home-Oricnted & 57 \\
Peer-Oricnted & 30 \\
Professionally-Oriented & 0 \\
Media-Oricnted & 33 \\
Multi-Source High & 70 \\
Multi-Source Low & 38 \\
Hybrid Pecr-Professional & 11 \\
Hybrid Pecr-Media & 16 \\
Hybrid Other & 15 \\
\hline
\end{tabular}

$\mathrm{X}^{2}=176.61, p<.00$.

*The two contact profiles are for human sexuality and birth control, and alcohol and smoking behavior.

was greater stability of styles across some styles than others. In general, multi-source high and low are reasonably stable, especially the former. About $70 \%$ of adolescents who are multi-source high for alcohol and smoking are the same for human sexuality and birth control. Of the single source styles, only home-oriented are relatively stable $(57 \%)$ across types of information. None of the adolescents with a professional style for alcohol and smoking has the same contact profile for human sexuality and birth control. In this case, however, the cell sizes are so small that we must be cautious in making generalizations from the data. None of the hybrid styles is stable across types of information.

Contact profiles are also significantly related to adolescent's message sending about human sexuality and birth control (H2). Table 3 shows that adolescents who feel the most comfortable advising own age peers are those with hybrid peer-media, multisource high, and home-oriented contact profile. Those who feel the least comfortable are the media-oriented and multi-source low. One might have expected more adolescents with peer-oriented profiles to feel comfortable advising friends. However, we

Table 3. Relationship Between Human Sexuality and Birth Control Contact Profiles and Advising Friends about Birth Control Behavior (Percentages)

HS and BC Contact Profiles

\begin{tabular}{|c|c|c|c|c|c|c|c|}
\hline $\begin{array}{l}\text { Advise } \\
\text { Friends } \\
\text { About BC } \\
\text { Behavior }\end{array}$ & $\begin{array}{c}\text { Home } \\
\text { Oriented } \\
(N=11)\end{array}$ & $\begin{array}{c}\text { Peer } \\
\text { Oricnted } \\
(N=18)\end{array}$ & $\begin{array}{c}\text { Media } \\
\text { Oriented } \\
(N=12)\end{array}$ & $\begin{array}{c}\text { Multi- } \\
\text { Source } \\
\text { High } \\
(N=68)\end{array}$ & $\begin{array}{c}\text { Multi- } \\
\text { Source } \\
\text { Low } \\
(N=30)\end{array}$ & $\begin{array}{c}\text { Hybrid } \\
\text { Peer-Media } \\
(N=24)\end{array}$ & $\begin{array}{c}\text { Hybrid } \\
\text { Other } \\
(N=27)\end{array}$ \\
\hline Yes & 70.0 & 47.4 & 25.0 & 79.1 & 46.7 & 91.3 & 66.7 \\
\hline No & 30.0 & 52.6 & 75.0 & 20.9 & 53.3 & 8.7 & 33.3 \\
\hline Totals & 100.0 & 100.0 & 100.0 & 100.0 & 100.0 & 100.0 & 100.0 \\
\hline
\end{tabular}

$$
x^{2}=28.88 . p<.00
$$


find that it is the adolescents with peer-media contact profiles who feel the most comfortable. We believe that these are adolescents who are peer-oriented but who also have information to share with friends. Adolescents with home-oriented contact profiles also are active in message sending about birth control. These perhaps are adolescents who feel high in self-esteem and are confident to give advice. ${ }^{14}$

Human sexuality and birth control contact profiles are significantly related to adolescents' information seeking about these topics (see Table 4). In general, adolescents with multi-source high and hybrid contact profiles engage in the most information seeking. These are adolescents with higher levels of contact with diverse sources. Adolescents with one single source profile, peer-oriented, also engaged in high levels of information secking about sexuality and birth control. We attribute this finding to the relevance of information of this type within peer networks. ${ }^{15}$

Contact profiles for human sexuality and birth control information are significantly related to an adolescent's capacity to make important health decisions (see Tables 5 and 6). Adolescents with multi-score high and hybrid peer-media profiles had the highest mean score for health decision making capacity. These are adolescents who are likely to have had high social interaction and potential for acquiring and considering diverse information. These opportunities over time can lead to overall improved health decision making. Not surprising, of the single source contact profiles, adolescents who were peer-oriented had higher scores than others. Adolescents with multi-source low contact profiles had the poorest capacity to make health decisions.

Differences in contact profiles for alcohol and smoking information and health decision making capacity were also significant. However, the pattern of relationships is quite different from that observed for human sexuality and birth control. Adolescents with home-oriented contact profiles had the highest decision-making score, suggesting that alcohol and smoking information can be discussed openly in the family, and perhaps family members can assist in decision making. Why those adolescents with professionally oriented contact profiles and those with peer-media ones had the lowest capacity to make health decision is not clear. Perhaps, media show alcohol use and smoking to be so much of a part of daily life, that peer-media adolescents do not feel that there are many questions to ask or decisions to make about their use. Professional sources are perhaps normative about alcohol use and smoking behavior and do not emphasize sufficiently decision-making about the topics.

Table 4. Relationship Between Human Sexuality and Birth Control Contact Profiles and Secking Bitth Control Information (Percentages)

HS and BC Contact Profiles

\begin{tabular}{|c|c|c|c|c|c|c|c|}
\hline $\begin{array}{c}\text { Information } \\
\text { Secking }\end{array}$ & $\begin{array}{l}\text { Home } \\
\text { Oricnted } \\
(N=11)\end{array}$ & $\begin{array}{c}\text { Peer } \\
\text { Oriented } \\
(N=18)\end{array}$ & $\begin{array}{c}\text { Media } \\
\text { Oriented } \\
(N-12)\end{array}$ & $\begin{array}{c}\text { Multi- } \\
\text { Source } \\
\text { High } \\
(N=68)\end{array}$ & $\begin{array}{c}\text { Multi- } \\
\text { Source } \\
\text { Low } \\
(N=30)\end{array}$ & $\begin{array}{c}\text { Hybrid } \\
\text { Peer-Media } \\
(N=24)\end{array}$ & $\begin{array}{c}\text { Hybrid } \\
\text { Other } \\
(N=27)\end{array}$ \\
\hline Yes & 18.2 & 44.4 & 8.3 & 63.2 & 10.0 & 62.5 & 63.0 \\
\hline $\mathrm{No}$ & 81.8 & 55.6 & 91.7 & 36.8 & 90.0 & 37.5 & 37.0 \\
\hline Totals & 100.0 & 100.0 & 100.0 & 100.0 & 100.0 & 100.0 & 100.0 \\
\hline
\end{tabular}

$$
X^{2}=39.69 . p<.00
$$


Table 5. Relationship Between Human Sexuality and Birth Control Contact Profiles and Health Decision-Making Capacity (Means)

\begin{tabular}{lc}
\multicolumn{1}{c}{$\begin{array}{c}\text { HS\&BC Contact } \\
\text { Profiles }\end{array}$} & Mean Score on D-M Index \\
\hline Home-Oriented $(N=11)$ & 5.0 \\
Peer-Oriented $(N=18)$ & 6.1 \\
Media-Oriented $(N=12)$ & 4.7 \\
Multi-Source High $(N=68)$ & 6.8 \\
Multi-Source Low $(N=30)$ & 4.6 \\
Hybrid Peer-Media $(N=24)$ & 6.7 \\
Hybrid Other $(N=27)$ & 6.4 \\
\hline
\end{tabular}

$F(6,187)=3.405, p<.00$

Contact profiles were also significantly related to awareness of and contact with a new information source (see Tables 7 and 8 ). Adolescents who had a hybrid peermedia contact profile for human sexuality and birth control were more likely than others to be aware of a new peer education program (for which there had been a modest media campaign) in the school on human sexuality and birth control. They were about twice as aware as adolescents with any of the single source contact profiles, including peer-oriented. Not surprisingly, adolescents with a multi-source high contact profile were also very likely to be aware of the new program. perhaps reflecting the many diverse sources available to them, including peers and media, to learn about it.

Adolescents with the most contact with a peer education program on human sexuality and birth control had multi-source high, peer-oriented and hybrid peer-media contact profiles. All three of these contact profiles have a strong peer-orientation. However, the hybrid peer-media profile does not provide any boost for contact as it did for awareness of the peer education program. Not a single adolescent with a home-oriented profile was in contact with a peer educator, suggesting that these adolescents did not know about or view peer educators as a information source.

Table 6. Relationship Between Alcohol and Smoking Contact Profiles and Health DecisionMaking Capacity (Mcans)

ALC and SMOK Contact Protiles

Mean Score on D-M Index

$\begin{array}{ll}\text { Home-Oriented }(N=7) & 7.4 \\ \text { Peer-Oriented }(N=13) & 6.8 \\ \text { Professionally-Oriented }(N=15) & 4.8 \\ \text { Media-Oriented }(N=9) & 6.2 \\ \text { Multi-Source High }(N=53) & 7.3 \\ \text { Multi-Source Low }(N=40) & 4.7 \\ \text { Hybrid Pecr-Professional }(N=19) & 5.8 \\ \text { Hybrid Per-Media }(N=10) & 4.5 \\ \text { Hybrid Other }(N=26) & 6.0\end{array}$

$F(8,183)=3.918, p<.00$. 
Table 7. Relationship Between Human Sexuality and Birth Control Contact Profiles and Awareness of HS and BC Pecr Education Program (Percentages)

\begin{tabular}{|c|c|c|c|c|c|c|c|}
\hline \multirow[b]{2}{*}{$\begin{array}{c}\text { Awareness } \\
\text { PEP } \\
\text { Program }\end{array}$} & \multicolumn{7}{|c|}{ HS and BC Contact Profiles } \\
\hline & $\begin{array}{c}\text { Home } \\
\text { Oriented } \\
(N=11)\end{array}$ & $\begin{array}{c}\text { Peer } \\
\text { Oriented } \\
(N=18)\end{array}$ & $\begin{array}{c}\text { Media } \\
\text { Oriented } \\
(N=12)\end{array}$ & $\begin{array}{c}\text { Multi- } \\
\text { Source } \\
\text { High } \\
(N=68)\end{array}$ & $\begin{array}{c}\text { Multi- } \\
\text { Source } \\
\text { Low } \\
(N=30)\end{array}$ & $\begin{array}{c}\text { Hybrid } \\
\text { Pcer-Media } \\
(N=24)\end{array}$ & $\begin{array}{c}\text { Hybrid } \\
\text { Other } \\
(N=27)\end{array}$ \\
\hline Yes & 27.3 & 31.6 & 41.7 & 64.7 & 29.0 & 75.0 & 51.9 \\
\hline No & 72.7 & 68.4 & 58.3 & 35.3 & 71.0 & 25.0 & 48.1 \\
\hline Totals & 100.0 & 100.0 & 100.0 & 100.0 & 100.0 & 100.0 & 100.0 \\
\hline
\end{tabular}

$\mathrm{X}^{2}=22.39 . p<.00$.

\section{DISCUSSION}

Information sources appear to be constructed by users of information according to the type of information needed. Contact profiles are important because they stand between the user and the information environment and affect message awareness and message use. They influence how a person attends to information and uses it in some beneficial way.

Profiles that include varied contact with the mass media, e.g., hybrid peer-media and multi-source profiles, seem to provide users with an informational boost. For adolescents, this often means high levels of awareness of health information sources related to human sexuality and birth control and increased likelihood of advising peers about birth control. Theoretically, adolescents with profiles that include a variety of mass media should be more readily reached by information campaigns that involve mass media. A mass media approach would fit better with their style than it would for adolescents with other styles, e.g.. mainly home-oriented or peer-oriented. Yet our findings suggest that it is adolescents with a hybrid peer-media contact profile who are affected more by a mass media campaign than adolescents with simply a mediaoriented profile. The former could be expected to have greater opportunities for social interaction about campaign information.

Table 8. Relationship Between Human Sexuality and Birth Control Contact Profiles and Talking to a Peer Educator about HS\& BC (Percentages)

\begin{tabular}{|c|c|c|c|c|c|c|c|}
\hline \multirow[b]{2}{*}{$\begin{array}{c}\text { Talk } \\
\text { Peer } \\
\text { Educator }\end{array}$} & \multicolumn{7}{|c|}{$\mathrm{HS}$ and $\mathrm{BC}$ Contact Profiles } \\
\hline & $\begin{array}{c}\text { Home } \\
\text { Oricned } \\
(N=11)\end{array}$ & $\begin{array}{c}\text { Peer } \\
\text { Oriented } \\
(N=18)\end{array}$ & $\begin{array}{c}\text { Media } \\
\text { Oriented } \\
(X=121\end{array}$ & $\begin{array}{l}\text { Multi- } \\
\text { Source } \\
\text { High } \\
(N=68)\end{array}$ & $\begin{array}{l}\text { Multi- } \\
\text { Source } \\
\text { Low } \\
(N=8)\end{array}$ & $\begin{array}{c}\text { Hybrid } \\
\text { Pecr-Media } \\
(N=16)\end{array}$ & $\begin{array}{c}\text { Hybrid } \\
\text { Other } \\
1 .=151\end{array}$ \\
\hline Yes & 0.0 & 50.0 & 40.0 & 55.8 & 10.0 & 50.0 & 40.0 \\
\hline No & 100.0 & 50.0 & 60.0 & 44.2 & 100.0 & 50.0 & 60.0 \\
\hline Totals & 100.0 & 100.0 & 100.0 & 100.0 & 100.0 & 100.0 & 100.0 \\
\hline
\end{tabular}

$\mathrm{X}^{2}=12.24 . p<.06$ 
Study data makc clear that a single cluster contact profile (e.g. , a peer-oriented one) is insufficient to guarantee that an adolescent will be aware of a potentially relevant source (e.g., a peer education program) or communicate about a specific topic with a highly relevant group (e.g., own-age peers). Multiple cluster profiles appear to have the edge because they have more opportunities for information and social interaction. This finding is important for health educators and other health communicators. Special strategies may be needed to reach and influence adolescents who depend on a single source for their information.

Data show that contact profiles do not generalize well across different health topics, except for the home-oriented and the multi-source high profiles. This finding suggests the need to determine contact profiles for different types of information before using them as variables in the study of communication effects.

Contact profiles are useful in explaining why some information campaigns fail while others succeed. ${ }^{16}$ Some fail because sources that are delivering campaign messages are not part of people's source constructiens; they do not form part of a pattern of contacts that the individual has acquired to obtain answers to questions he or she has on topics of interest. We found some evidence for this view in the fact that adolescents with home-oriented contact profiles did not contact peer educators who were available to talk to them about human sexuality and birth control in their school. The issue here did not appear to be the availability of an information source. nor the assumed appropriateness of one, but the message seeking behavior of particular adolescents.

Measures of contact profiles need to be improved in further research. First, the closed-ended question format which we used perhaps missed some of the sources actually used by adolescents. Open-ended questions concerning contact with various sources could be used to uncover additional sources contacted.

Second, the present coding scheme does not distinguish between sources contacted that have been very helpful and those which have not. Some criterion could be developed to include in the coding scheme the relative usefulness of sources.

Third. an improved measure of contact profiles would also take into account the amount of contact with a particular source. Weighting profiles by the number of repeated contacts with a particular source is one possibility. This would make certain categories of frequent contact appear more prominent.

Further research on contact protiles is needed to validate the concept and determine its potential usefulness in the study of health communication. The concept seems to be a useful one to employ in the design and implementation of information programs. Knowing a population's contact profiles would aid in designing an outreach strategy for a particular subgroup or illustrate the need for multiple strategies to reach larger populations. In either case, the emphasis would be on improvement of the information delivery system. The outcome could be an improvement in the fit between health information that is available in the information environment and the subjective needs of users.

\section{References}

1. McGuire WJ: The nature of attitudes and attitude change, in G Lindzey. E Aronson (eds): The Handbook of Sorial Psychology (ed 2. vol 3). Reading. MA. Adison Wesley. 1969

2. McGuire WJ: Persuasion, resistance and attitude change. in IS Porl. W Schramm (eds): Handbook of Commanication. NY. Rand McNally College Publishing Co.. 1973. 
3. McGuire WJ: Theoretical foundations of campaigns, in WJ Paisley. RE Rice (eds): Public Communication Campaigns, Beverley Hills, Sage Publications, 1981.

4. Dervin B: Mass communication: Changing conceptions of the audience, in W Paisley, R Rice (eds): Public Communicatio Campaigns. Beverley Hills. Sage Publications, 1981.

5. Dervin B. Harlock S, Atwood R, et al: The human side of information: An exploration in a health communication context, in D Nimmo (ed): Communication Yearbook 4. New Brunswick. NJ: Transactions. 1980.

6. Dervin et al: Improving predictions of information use: A comparison of predictor types in a health communication setting, in M Burgoon (ed): Communication Yearbook 5. New Brunswick. NJ, Transactions, 1981.

7. Dervin, B. Jacohson. TL, Nilan, MS: Measuring aspects of information seeking: A test of a quantitative/qualitative methodology, in $\mathrm{M}$ Burgoon (ed): Communication Yearbook 6. Beverley Hills, CA. Sage Publications. 1982.

8. Slesinger D: The utilization of preventive medical services by urban black mothers, in D Mechanic (ed): The Grow'th of Bureaucratic Medicine, New York, John Wiley \& Sons, 1976.

9. Wan T, Gray L: Differential access to preventive services for young children in low income urban areas. Journal of Health and Social Behavior 19:312-324, 1978.

10. Greeno JG: Language. understanding and leaming. Paper presented at the Symposium on Individual Differences. Cognition and Leaming, American Association for the Advancement of Science, Denver. Colorado, 1977.

11. Rogers EM: Communication strategies for family planning. New York, Holt, Rinehart and Winston, 1973.

12. DePietro RA. Hacker S. Hicks JC, et al: Female adolescents ' communication activity and conditions of birth control use over time. Studies in Family Planning Dept. of Health Behavior and Health Education, University of Michigan School of Public Health.

13. Farace RV. Monge PR, Russel HM: Communicating and organizing. Reading, MA, Adison-Wesley, 1977.

14. De Pietro RA, Clark N: Adolescents' communication styles for learning about birth control from mass media. Health Education Quarterly, 10(2):106-119. 1983.

15. Cams D: Talking about sex: notes on first coitus and the double standard. Journal of Marriage and the Family. 35(4):677-688, 1973.

16. Paisley WJ: Public communication campaigns: the american experience, in WJ Paisley and RE Rice (Eds), Communication Campaigns. Beverley Hills, CA, Sage Publications, 1981. 